\title{
Marcus Faria Figueiredo (1942-2014)
}

Ao longo dos meses de campanha, neste ano eleitoral de 2014, não foram poucos os sobressaltos dos analistas de conjuntura, tanto cientistas políticos profissionais quanto a legião de especialistas amadores em que os brasileiros se transformam, dizem, em períodos de Copa do Mundo e eleições presidenciais. Neste cenário, faz falta a reflexão ponderada e sintética do professor Marcus Figueiredo, profundo conhecedor do comportamento e humores do eleitor brasileiro, estudioso desassombrado das suas condicionantes.

Ele confiava bastante na razoabilidade do cidadão comum; embora seus estudos mostrassem com clareza o impacto da campanha eleitoral, e particularmente do horário de TV e rádio, sobre as intenções de voto para presidente, não atribuía essa dinâmica a uma influência direta do marketing político sobre eleitores manipuláveis. As campanhas movimentam-se dentro dos limites retóricos da realidade; embora sejam "construções ficcionais", os mundos possíveis oferecidos pelos candidatos necessitam refletir os conhecimentos e expectativas dos eleitores, ou não serão verossímeis. As campanhas eleitorais são o momento máximo de informação e participação política para a maioria dos cidadãos brasileiros, período em que a onda de interesse envolve até os cidadãos menos engajados. Nesse contexto, Marcus sempre chamou atenção para a perspectiva multicausal própria das ciências

\footnotetext{
* É professora de Comunicação da Universidade do Estado do Rio de Janeiro (Rio de Janeiro, RJ, Brasil). E-mail: a.alde@uol.com.br.
} 
sociais, em que o contexto social e econômico, a avaliação do governo e das alternativas partidárias, na medida em que são conhecidas, permitem e limitam ondas de interesse e mudança de opinião. $\mathrm{Na}$ atual conjuntura, estaria acompanhando com animação - e maquiavélica prudência - as reviravoltas das opiniões e análises.

Não tivemos, nem ele nem nós, essa oportunidade. Marcus faleceu às vésperas do $9^{\circ}$ Encontro da Associação Brasileira de Ciência Política - dois dias antes do seu início, no último mês de agosto. Os dias do congresso, especialmente na Área Temática de Comunicação e Opinião Pública, transcorreram com várias homenagens e memórias emocionadas do colega, professor, orientador e amigo de tantos dos presentes. Foram lembradas facetas reveladoras da sua personalidade, como seu gosto pelo Flamengo e pelas novelas, seu rigor e generosidade como orientador, sua presença assídua no "grupo da esbórnia" forjado à beira da piscina do hotel Glória em tantos congressos da ANPOCS.

Ao longo de 72 anos de vida e 50 de carreira, Marcus Figueiredo conseguiu compatibilizar uma produção intelectual significativa com uma fecunda atividade de orientação, além de ter participado profissionalmente de várias campanhas como consultor e analista. Em entrevista à Revista Compolítica (http://compolitica.org/revista/index.php/revista/article/view/55/36), já havíamos recuperado parte dessa trajetória.

O valor de sua contribuição tem um dos principais marcos na publicação de sua tese de doutorado, $A$ decisão do voto, escolhida como melhor tese de Ciência Política pela ANPOCS em 1989, e publicada dois anos depois em parceria com a Sumaré. Sobre ela, Wanderley Guilherme dos Santos escreve, no prefácio à obra, que "o autor produziu um estudo que faz com que pelo menos uma das áreas Típicas da Ciência Política - o estudo de comportamento eleitoral - se ajuste aos padrões internacionais contemporâneos da disciplina [... e] um conjunto de capítulos sem paralelo na produção recente de politicólogos brasileiros". O trabalho, recentemente republicado pela Editora UFMG, continua sendo uma referência para os estudos sobre comportamento eleitoral, e é emblemático do estilo do autor, com sua capacidade de sintetizar questões teóricas até o esqueleto mais essencial, para depois aplicar-lhes o teste do raciocínio lógico rigoroso.

Publicada apenas em 1991, a tese é resultado de um trabalho iniciado anos antes, em 1976, quando Marcus e Argelina Figueiredo partiram para 
realizar estudos doutorais nos Estados Unidos, seguindo o percurso de outros jovens pesquisadores empenhados na compreensão e análise dos fenômenos ligados ao sistema político e ao processo de redemocratização então em curso no Brasil. Ainda eram poucos os doutorados no país, e universidades como a de Chicago e a de Michigan, concentrando acadêmicos americanos e europeus de primeira grandeza, contribuíram para formar muitos dos cientistas sociais dessa geração.

Nascido em 1942, Marcus interessara-se por política através da militância no movimento estudantil. Em 1965, aos 23 anos, começou a estudar Física na PUC, mas logo abandonaria o curso para dedicar-se à militância política e à pesquisa. Em 1967, ingressou no curso de Economia da Faculdade Candido Mendes, que também não concluiria. Em 1968, finalmente, escolheu o curso de Ciências Sociais da UFF, que naquele momento, no auge da ditadura militar, abrigava um grupo importante de jovens professores críticos ao regime. Estela Maria da Silva, Francisco Ferraz, Celina do Amaral Peixoto, Neuma Aguiar e Luiz de Castro Farias foram alguns dos professores significativos na formação daqueles jovens pesquisadores.

Nessa época, por intermédio do amigo Cesar Guimarães, que conhecera no movimento estudantil, e de Bolívar Lamounier, que estava no IUPERJ, Marcus aproximou-se do instituto, onde passou a estagiar como assistente de pesquisa, trabalhando também com Wanderley Guilherme dos Santos. O IUPERJ havia sido criado no âmbito da Faculdade Candido Mendes como um centro de excelência e pensamento crítico diante das questões políticas e sociais colocadas pelo regime autoritário, e tornou-se um importante refúgio para intelectuais brasileiros comprometidos com a democracia. Para Marcus, seria um vínculo duradouro.

Marcus logo confirmou seu gosto e vocação para a pesquisa. Tinha facilidade para perceber temas emergentes e possibilidades de investigação. Graças a conhecimentos pessoais, por exemplo, teve acesso à biblioteca de Almir de Andrade, um dos principais diretores do DIP durante o Estado Novo, o que resultaria na pesquisa "Cultura política: revista teórica do Estado Novo", publicada como artigo na recém-fundada revista Dados, do IUPERJ, em 1968 - antes mesmo de iniciar a graduação na UFF. Sua dissertação de mestrado, orientada por Cesar Guimarães e defendida no IUPERJ em 1975, versava sobre a política de coação no regime militar e seria publicada em 1978 no volume Legitimidade e coação no Brasil Pós-64, que trazia também 
o trabalho de Lúcia Klein. No currículo Lattes, o trabalho consta como uma de suas cinco contribuições mais relevantes.

Com o processo de redemocratização, os estudos em Ciência Política voltaram-se crescentemente para questões como eleições e partidos, que se tornavam centrais com a perspectiva de consolidação dos direitos políticos. Marcus e Argelina Cheibub haviam se casado em 1972, e quatro anos depois decidiram partir para os Estados Unidos com a filha Camila, de seis meses. Inicialmente, Marcus havia pensando em estudar na Universidade de Michigan, que conhecera no ano anterior cursando o Summer Program in Political Reseach. Argelina, que preferia Chicago, disse que não foi difícil convencê-lo após seis meses de experiência na cidade. $\mathrm{O}$ ambiente urbano e cosmopolita certamente teve seu peso, mas também contou a qualidade do Departamento de Ciência Política da Universidade de Chicago, talvez o principal centro de estudos em ciência política naquele momento, onde os pesquisadores brasileiros fizeram cursos com David Easton, Arthur Stinchcombe, Brian Barry, Jon Elster e outros. Com a dupla orientação de Philippe Schmitter e Adam Przeworski, Marcus desenvolveu nos Estados Unidos, com bolsa do CNPq, a pesquisa sobre a decisão do voto. Depois de três anos e meio, em 1979, contudo, ele e Argelina voltariam ao Brasil com "tudo pronto, menos a tese".

Só anos mais tarde Argelina voltaria para Chicago, onde terminou a tese Political coalitions in Brazil 1961-1964: democratic alternatives to the political crisis, defendida em 1987. Marcus levaria seu projeto, praticamente concluído, para a USP, doutorando-se, finalmente, em 1989, sob supervisão de Maria Teresa Sadeck.

Antes disso, de volta ao Rio de Janeiro, Marcus continuou trabalhando como assistente de pesquisa no IUPERJ, e publicando em conjunto com Amaury de Souza e Nelson do Valle Silva, principalmente sobre comportamento eleitoral e metodologia de pesquisa.

Em 1983, uma oportunidade dupla se apresentaria. Argelina passou em concurso para a UNICAMP, e Marcus foi convidado por Bolívar Lamounier para integrar o IDESP, onde permaneceria até 1989, contribuindo para desenvolver a pesquisa aplicada do instituto, tanto sobre comportamento eleitoral e opinião pública, quanto na área de avaliação de políticas públicas. Data desse período, por exemplo, o trabalho mais citado entre as publicações de Figueiredo, escrito em parceria com Argelina: "Avaliação política e avaliação de políticas: um quadro de referência teórica”, publicado na revista Análise \& 
Conjuntura em 1986. A obra logo se tornou uma importante referência para a área de estudos, exemplificando outra qualidade intelectual do Marcus: sua capacidade de construir grandes quadros sintéticos e abrangentes, resumos objetivos de situações complexas.

Ainda em São Paulo, também atuou na USP, entre 1990 e 1992, como professor visitante e bolsista recém-doutor, ensinando metodologia e teoria política para a pós-graduação. Na UNICAMP, foi orientador do Centro de Estudos de Opinião Pública (CESOP) a partir de 1992, sendo nomeado membro do Conselho Superior e, posteriormente, presidente. No CESOP, Marcus contribuiu para a organização dos bancos de dados e sua disponibilização ao público acadêmico, trabalhando principalmente com Rachel Meneguello. Seu empenho também foi fundamental para estabelecer uma parceria inédita entre a UNICAMP e institutos de pesquisa como o IBOPE e a Vox Populi, que passaram a compartilhar dados obtidos em pesquisas de mercado, enriquecendo o acervo do CESOP.

Em 1992, com a saída de Olavo Brasil para a UFMG, o IUPERJ perdeu sua principal referência no estudo do comportamento eleitoral, e abriu-se caminho para que Marcus voltasse ao instituto como professor. Ao longo dos anos, além de pesquisador e metodólogo, também se notabilizou como orientador, tendo supervisionado alguns trabalhos significativos na interface entre comportamento eleitoral e comunicação política. Afinal, com as práticas democráticas já consolidadas, permanece a importância das questões relativas à decisão do voto, uma vez que ainda hoje nos surpreendermos com contingências eleitorais inesperadas.

Foi durante os anos 1990 que Marcus mais atuou profissionalmente em campanhas eleitorais, sempre trabalhando como consultor e analista de pesquisa, assessorando diretamente os publicitários. A primeira, e uma das mais marcantes, foi a de Ulysses Guimarães em 1989. A partir daí, primeiramente a convite de Geraldo Walter, publicitário baiano ligado à PROPEG, atuou em várias campanhas majoritárias, como as campanhas presidenciais de Angola em 1992 e de FHC em 1994 e 1998, entre outras. Nesse sentido, ao se aproximar dos temas da comunicação, Marcus nunca deixou de ser cientista político, apontando para a relatividade dos efeitos da mídia e incorporando um amplo quadro de referências internacionais para enriquecer o debate. Por outro lado, trazia o repertório e realidade das campanhas para a discussão acadêmica. Jornalismo e propaganda, assim, não neutralizam o 
contexto político, mas só podem ser compreendidas, justamente, a partir da análise histórica e de conjuntura. Contra a visão paranoica dos apocalípticos, Marcus advogava a coerência e razoabilidade do cidadão comum.

Essa perspectiva informada e objetiva, que considera as diversas variáveis envolvidas no comportamento político - e nos resultados eleitorais - é algo que unifica, de certa forma, a produção intelectual de seus orientandos. Como mostram os dados e gráficos do Diretório da Compolítica (http:// compolitica.org/revista/index.php/revista/article/view/110), Marcus não foi apenas um orientador produtivo, com grande número de orientandos. Nesse sentido, outros professores começaram antes e orientaram mais gente. O que chama a atenção na análise desses gráficos são principalmente os desdobramentos e capilaridade da atividade de orientação. Ao supervisionar mais de 30 trabalhos no IUPERJ - 19 de doutorado e 13 de mestrado -, a maioria sobre comunicação política e comportamento eleitoral, Marcus tornou-se um ponto de convergência, estabelecendo vínculos com outras instituições e pesquisadores. Muitos de seus orientandos, por sua vez, já se estabeleceram por sua vez como orientadores em outras instituições. Considerando a especialidade da Comunicação Política no Brasil, embora haja pesquisa desde os anos 1970 e ela seja numericamente mais significativa na área de Comunicação, nenhum conjunto de trabalhos se assemelha mais a uma "escola" do que a produção de Marcus Figueiredo e seus orientandos.

É claro que essa capacidade de atração deveu-se também a sua inserção no IUPERJ como professor, a partir de 1992. Um ambiente intelectual excepcional, o instituto concedia grande liberdade aos pesquisadores, dedicados apenas à pós-graduação e brindados com alunos selecionados entre os mais brilhantes e interessados do país, todos com financiamento. Marcus sempre elogiou o ambiente acadêmico plural do IUPERJ, onde, segundo ele, era possível conviver dialeticamente com pensamentos, abordagens e metodologias de todos os tipos.

Nesse ambiente estimulante, deveu-se à sensibilidade particular do Marcus, no entanto, atender e coordenar a demanda de alguns alunos que, em meados dos anos 1990, convergiam no desejo de estudar a comunicação a partir da perspectiva da Ciência Política. Marcus teve a capacidade de agregar a esse impulso seu vasto conhecimento sobre comportamento político-eleitoral e estratégias de campanha, dando origem ao Doxa, o Laboratório de Pesquisa em Comunicação Política e Opinião Pública, que logo se tornou uma referência na 
pesquisa sobre propaganda eleitoral, monitoramento de cobertura jornalística das eleições e nos estudos sobre efeitos e dinâmicas da comunicação política. Trabalhando como grupo de forma sistemática a partir de 1996, inicialmente formado por Heloísa Dias, Vladimyr Lombardo Jorge e por mim, sob orientação do Marcus, o Doxa teve papel pioneiro na pesquisa em comunicação política, contribuindo principalmente para o reconhecimento da especialidade na área de Ciência Política e para seu amadurecimento metodológico.

Fisicamente, o Doxa chegou a funcionar em um velho prédio na rua São Clemente em que o IUPERJ armazenava móveis e papéis sem serventia. Sentávamos à frente de um monitor de TV de tubo, na sala empoeirada, assistindo repetidamente, exaustivamente, aos comerciais eleitorais dos candidatos a prefeito. Trabalhando junto com os estudantes, comparando as estratégias entre si e com as expectativas teóricas, desenvolvendo e sofisticando categorias analíticas, Marcus nos ensinou muito ali sobre o ofício da pesquisa empírica. Ao mesmo tempo, buscávamos referências externas teóricas e práticas, pois se tratava ainda de nossas primeiras experiências com eleições e campanhas livres - em 1996, por exemplo, analisamos a primeira vez que foram usadas as inserções curtas, de 30 e 60 segundos, de linguagem e alcance bastante diferentes dos tradicionais programas eleitorais. O resultado dessa pesquisa estava entre os que Marcus considerava os mais relevantes de sua produção. Efetivamente, o texto circulou primeiro internamente, na Série Estudos do IUPERJ (vol. 100); depois foi publicado como artigo na revista Opinião Pública (CESOP) e republicado na coletânea Marketing político e opinião pública, organizada por Rubens Figueiredo.

A partir dessa constatação - a importância crescente da comunicação de massa como variável política e eleitoral -, Marcus empenhou-se na consolidação e institucionalização da especialidade. Foi fundador, em 1998, com Vera Chaia, Fernando Azevedo e outros, do GT Mídia, Opinião Pública e Eleições da ANPOCS. Com diferentes nomes e composições, o GT firmou-se como um espaço de discussão vital para os pesquisadores, que já contavam com espaço equivalente no GT Comunicação Política da COMPÓS. Em 2008, foi o momento de articular a criação da AT Comunicação Política e Opinião Pública na ABCP, durante seu $4^{\circ}$ Encontro, em Campinas. Marcus também apoiou a criação da Associação Brasileira de Pesquisadores em Comunicação e Política (Compolítica), da qual foi sócio fundador - e as duas presidentes mais recentes, Luciana Veiga e Alessandra Aldé, foram ambas suas orientandas. 
Além da sensibilidade para as inovações tecnológicas e temáticas na pesquisa, Marcus tinha um enorme senso de responsabilidade em termos da difusão científica. A partir de 2000, quando começou a acompanhar a cobertura que os jornais impressos faziam das eleições, o Doxa notabilizou-se pela divulgação on-line dos resultados parciais, contribuindo assim para o debate público nas eleições. O acervo de material audiovisual de campanha, gradualmente ampliado e digitalizado, foi cedido para e copiado por vários pesquisadores, servindo de base para numerosas teses, dissertações e trabalhos acadêmicos em todos os níveis, no Brasil e no exterior. Em 2010, mais um fruto dessa preocupação com a difusão científica viria a público: o documentário Arquitetos do poder, projeto do qual foi coordenador-geral e que tem contribuído para esclarecer o público e informar o debate eleitoral. Foi responsável pela criação da revista da ABCP, a Brazilian Political Science Review, e um de seus primeiros editores. Defendeu enfaticamente que a publicação fosse on-line e em inglês: somente assim, acreditava, a produção acadêmica brasileira poderia circular de forma mais abrangente e ambicionar um diálogo internacional.

No IUPERJ, foi também diretor de Pesquisa e de Seminários e Publicações do IUPERJ, cargo em que acompanhou a crise institucional junto à Universidade Candido Mendes, e à frente do qual apoiou a migração para a UERJ em 2010. Seus últimos orientandos já defenderam teses sob a sigla IESP-UERJ.

Durante os anos no IUPERJ, Marcus conviveu com colegas que admirava, alguns dos quais foram também grandes amigos. A dedicatória do livro $A$ decisão do voto revela um pouco dessas dívidas intelectuais e afetivas ao declarar: "Ao Wanderley, que me ensinou a pensar; ao Nelson, que me ensinou a contar; à Argelina, que me ensinou a viver; à Camila e Joana que são os motivos para continuar." Também nos sugere algo sobre o lugar da família e dos afetos nessa construção. De minha parte, sempre admirei a relação com Argelina e outras tantas mulheres poderosas, relação de companheirismo e respeito mútuo. Mulheres que continuaram ocupando espaços afetivos e profissionais na vida do Marquinhos, desde a sucessão de apenas filhas e netas, filhas das filhas; até a disputa afetuosa entre as orientandas pelo posto de "mais queridas".

Marcus tinha facetas contraditórias: era piadista, um bon vivant; mas podia ser rabugento e intratável, e era sem dúvida muito teimoso. Os alunos inicialmente o temiam, mas assistir a suas aulas era sempre um desafio ao raciocínio e ao desenvolvimento do pensamento. Seu estilo era objetivo e 
direto, mas valia a pena seguir o seu raciocínio, sempre surpreendentemente iluminador. A síntese e clareza eram uma exigência consciente: o professor dizia que qualquer ideia podia ser resumida em dez linhas, e ameaçava não ler se os alunos escrevessem mais do que as dez páginas demandadas como trabalho de final de curso. Quando o conheci, como professor da disciplina de Partidos Políticos, no mestrado, não foram poucas as vezes que debatemos acaloradamente. Escrevi sobre o Marcus, nos agradecimentos da minha própria tese, palavras que até hoje resumem bem o que sinto por ele: "Sua inteligência, abertura mental e respeito pelo pensamento do outro são um constante estímulo para o trabalho autônomo e criativo. Sua cultura, objetividade e rigor metodológico, por outro lado, perpassam todo o trabalho, exigindo as escolhas e explicações que lhe dão intenção científica. Mas agradeço ao Marcus, principalmente, a conquista - gradual, discreta e segura - de uma amizade que no início me parecia tão improvável.”

Essa amizade, uma vez conquistada, foi sólida e duradoura. Marcus era uma companhia divertida e carinhosa, amigo das crianças e festividades. Foi um privilégio ter convivido e aprendido com ele. A riqueza desse legado - um saldo positivo, construído em comum - contribui para dimensionar a nossa perda. Há muito tempo, os próximos - alunos, amigos, familiares - convivemos e nos preocupamos com a saúde frágil do Marcus. Com uma condição circulatória geneticamente instável, cada campanha eleitoral de que participou representava para ele um pico de alta voltagem, geralmente cobrado imediatamente na forma de "um avecezinho". Com o tempo, diminuiu sua atuação mais intensa como analista e passou a atuar de longe, apenas como observador, comentando para a mídia.

No $4^{\circ}$ Encontro da Compolítica, em 2011 na UERJ, o programa previa que ele seria o conferencista de abertura, mas sofreu mais um episódio médico alguns dias antes e não pôde falar. Assim, foi um privilégio tê-lo, em 2013, à frente do GT de Mídia e Eleições do $5^{\circ}$ Encontro da Compolítica, em Curitiba, conduzindo os trabalhos e debatendo com os participantes, produtivo e animado.

Para mim, a parte mais importante do legado intelectual do Marcus Figueiredo é o respeito democrático pelo eleitor, pelo homem comum; nas suas palavras, os "milhares de anônimos que mudam a história através do voto". Entender suas razões e os motivos de suas decisões continuam sendo uma missão inevitável de uma ciência política verdadeiramente democrática. 